Revista Iberoamericana. Vol. LXIII, Núm. 180, Julio-Setiembre 1997; 341-344

\title{
MESTIZAJE E HIBRIDEZ: \\ LOS RIESGOS DE LAS METÁFORAS. APUNTES
}

\author{
POR \\ Antonio CoRnejo-Polar \\ University of California-Berkeley \\ Universidad Nacional Mayor de San Marcos
}

No hace mucho Fernández Retamar alertó contra los peligros implícitos en la utilización de categorías provenientes de otros ámbitos a los campos culturales y literarios. El préstamo metafórico y/o metonímico puede conducir a confusiones sin cuento. Por mi parte recuerdo que un sector nada desdeñable de las rigideces estéticas del marxismo provino de la lectura denotativa de lo que en realidad eran metáforas extraídas de la ciencia del XIX: un ejemplo basta, el concepto de "reflejo".

Es evidente que categorías como mestizaje e hibridez toman pie en disciplinas ajenas al análisis cultural y literario, básicamente en la biología, con el agravante - en el caso del mestizaje - que se trata de un concepto ideologizado en extremo. En lo que toca a hibridez la asociación casi espontánea tiene que ver con la esterilidad de los productos híbridos, objeción tantas veces repetida que hoy día García Canclini tiene una impresionante lista de productos híbridos y fecundos ... De cualquier manera esa asociación no es fácil de destruir. De hecho, en el diccionario Velázquez inglés-español la palabra híbrido suscita de inmediato una acepción algo brutal: "mula". Por supuesto que reconozco que el empleo de estos préstamos semánticos tiene riesgos inevitables; al mismo tiempo considero que detrás de ellos como que se desplaza una densa capa de significación que engloba y justifica cada concepción de las cosas. Incluso estaría tentando de afirmar que una lectura de ese sustrato de significado es más productiva que la simple declaración de ajenidad e impertinencia de las categorías empleadas para esclarecer un punto concreto.

Varias veces he comentado que el concepto de mestizaje, pese a su tradición y prestigio, es el que falsifica de una manera más drástica la condición de nuestra cultura y literatura. En efecto lo que hace es ofrecer imágenes armónicas de lo que obviamente es desgajado y beligerante, proponiendo figuraciones que en el fondo sólo son pertinentes a quienes conviene imaginar nuestras sociedades como tersos y nada conflictivos espacios de convivencia. En otra ocasión también me he detenido en el mal uso de la vida y obra de Garcilaso como mestizo simétrico de una nación tan mezclada que ya formaría una unidad sin fisuras.

Añado que - pese a mi irrestricto respeto por Ángel Rama — la idea de transculturación se ha convertido cada vez más en la cobertura más sofisticada de la categoría de mestizaje. Después de todo el símbolo del "ajiaco" de Fernando Ortiz que reasume Rama bien puede ser el emblema mayor de la falaz armonía en la que habría concluido un proceso múltiple de mixturación. Aclaro que en modo alguno desconozco las obvias o subterráneas 
relaciones que se dan entre los diversos estratos socio-culturales de América Latina; lo que objeto es la interpretación según la cual todo habría quedado armonizado dentro de espacios apacibles y amenos (y por cierto hechizos), de nuestra América.

Advierto, de otro lado, que la teoría de la hibridez de García Canclini, aunque a veces afeada por el tono celebratorio con el que está dicha y por el excesivo empleo de ejemplos que parecen referirse preferentemente a ciertos estratos de la sociedad latinoamericana, tiene una virtud poco reconocida y para mí incuestionable: su inmersión en la historia, lo que permite que así como se "entra y sale de la modernidad" también se pueda — de algún modo- entrar y salir de la hibridez, aunque estos tránsitos no siempre obedezcan a las necesidades, o a los intereses o a la libertad de quienes los realizan.

Me gustaría subrayar, de otro lado, que las categorías mencionadas, cuyo anclaje semántico corresponde a otras disciplinas, no dejan de ser tan conflictivas como aquellas otras categorías que parecen sustentarse en el propio ejercicio crítico: "literatura heterogénea", "literatura alternativa", "literatura diglósica", etc. No rememoro la conocida frase de Goethe sobre el árbol de la vida, pero remarco lo que es obvio: ninguna categoría crítica devela la totalidad de la materia que estudia y — sobre todo- la categoría en cuestión corresponde a un orden de distinta índole con relación a esa materia. Pera seguir con lo evidente, ninguna de las categorías mencionadas resuelve la totalidad de la problemática que suscita y todas ellas se instalan en el espacio epistemológico que - inevitablementees distante y distinto.

Probablemente existan diversos grados de aproximación entre los mencionados conceptos y la esfera de la producción estética, pero se trata de cercanías de alguna manera engañosas porque de cualquier forma las dos mantendrán su fijación en el ámbito que les es propio. En este orden de cosas me interesa enormemente el intento de trabajar ciertas literaturas étnicas empleando formas de conciencia que serían propias de esos ámbitos antropológicos; sin embargo el problema - si es que fuera problema-no se resuelve. Me estoy refiriendo no a la filología que intenta definir los géneros que se habrían empleado antes de la Conquista, que es parte del meritorio trabajo de Garibay, López Portilla, Lara o Vidal Martínez, sino al esclarecimiento de ciertas dimensiones de la conciencia de los pueblos americanos que explicarían la índole de algunas de sus manifestaciones discursivas más complejas. Tinku, Pachakuti, Wakcha, para el mundo andino, serían en este orden de cosas las bases que harían posible la comprensión más íntima de esos universos discursivos.

La idea, como digo, me interesa, y creo que puede ser efectivamente productiva. Sin embargo, me pregunto si saliendo de una excentricidad no estamos entrando en otra; o lo que sería peor, si no estamos repitiendo las posiciones metafísicas de teóricos como Steiger para quien cada género correspondía a una forma de experiencia de vida. Desamparo, pobreza, forasterismo (wakcho), son experiencias que no veo bien cómo se trasvasarían a la configuración de los discursos étnicos que hacen mención o parten de esas experiencias. En otras palabras, admito con entusiasmo su capacidad hermenéutica pero no llego a observar su rendimiento teórico. Finalmente apunto que tal vez en el fondo la relación entre epistemología crítica y producción estética sea inevitablemente metafórica.

A esta altura quisiera hacer una propuesta tangencial pero - imagino- esclarecedora. El ingreso o salida de la modernidad y al mismo tiempo de la hibridez tiene una ruta especialmente transitada en los estudios culturales y literarios. No aludo ahora al viejo 
reclamo de autonomía teórico-metodológica; me refiero — más escuetamente- a la difícil convivencia de textos y discursos en español y portugués (y eventualmente en lenguas amerindias) con la incontenible diseminación de textos críticos en inglés (o en otros idiomas europeos). Por supuesto que no intento ni remotamente postular un fundamentalismo lingüístico que sólo permitiría hablar de una literatura en el idioma que le es propio, pero sí alerto contra el excesivo desnivel de la producción crítica en inglés que parece - bajo viejos modelos industriales - tomar como materia prima la literatura hispanoamericana y devolverla en artefactos críticos sofisticados. No puedo en esta instancia revisar todas las repercusiones de este hecho. Permítanme señalar al azar algunas:

a) Los textos críticos en inglés suelen utilizar bibliografía en el mismo idioma y prescindir, o no citar, lo que trabajosamente se hizo en América Latina durante largos años. Por lo demás su extrema preferencia por el estrecho canon teórico posmoderno es una compulsión que puede llegar hasta el ridículo.

b) Puesto que el espacio "natural" de los estudios latinoamericanos es América Latina se está realizando algo así como una subdivisión de la disciplina, habida cuenta que es absolutamente erróneo que la mayoría de profesores hispanoamericanos de su literatura conozcan suficientemente el idioma inglés. Así, ciertos aportes sajones no ingresan, o ingresan tarde, a la tradición crítica latinoamericana. Naturalmente el otro lado de la disciplina adquiere su propio ritmo y define sus propios cánones.

c) El masivo empleo de una lengua extranjera para el estudio de la literatura hispanoamericana está suscitando además - aunque tal vez nadie lo quiera - un extraña jerarquía en la que los textos de esta condición resultan gobernando el campo general de los estudios hispanoamericanos. Me temo, en este sentido, que estamos generando una extraña crítica diglósica.

d) Aunque tal vez sea un fenómeno independiente no hay modo de dejar de mencionar que se ha producido un dramático declive en los niveles de empleo del español tanto en profesores como en estudiantes. Es probable que ésta sea una de las razones que explican la proliferante producción en inglés - lo que sin duda se combina con el prestigio de la crítica hecha en ese idioma. Me siento algo arqueológico al decirlo pero la verdad es que tengo nostalgia por aquellas antiguas épocas en las que la primera obligación del profesor y/o estudiante de español, pero también su máximo orgullo, era dominar a la perfección el español. Aclaro de inmediato que no me refiero en absoluto a la nacionalidad del profesor y/o del estudiante. No se me oculta que profesores hispanos o de origen hispano tienen y hasta más agudamente a veces - este mismo problema.

e) Todo lo anterior se relaciona asimismo con el notable incremento de actividades académicas y cursos propios de los Departamentos de Español que actualmente se realizan en inglés. No puedo entrar ahora en tema tan espinoso pero me temo mucho que estudios culturales, poscoloniales y/o subalternos no han calibrado lo que implica el practicar esas disciplinas en una sola lengua cualquiera que sea el idioma de los discursos examinados. En cierto sentido los problemas más generales comienzan a percibirse desde la óptica parcial de la cultura cuyo idioma se utiliza, con el agravante de que por obvias razones los textos originales quedan desplazados por traducciones que no siempre son confiables.

f) Confieso que no tengo solución a cómo resolver el problema que acabo de mencionar, pero sí tengo plena conciencia que detrás de las mejores buenas intenciones se 
está produciendo una falsa universalización de la literatura a partir del instrumento lingüístico con que se le trabaja. Sin quererlo estamos arañando de nuevo la idea de "literatura universal" sólo que esta vez se trataría de un extraño artefacto totalmente hecho en inglés — precisamente - en el idioma de la hegemonía que habla para sí de lo marginal, subalterno, poscolonial.

g) No quiero dejar de mencionar que mis palabras no implican que la crítica escrita en español sea siempre de buena calidad. Las dictaduras primero, con la censura o métodos harto más brutales, y el neoliberalismo después con su política de pauperización de las instituciones culturales públicas (universidades, bibliotecas, archivos) prácticamente han destruido las bases materiales para el desarrollo de la disciplina, aunque también hay que reconocer la situación disímil de cada país y las obvias diferencias de proyectos grupales y personales.

Declaro que puede haber en mis palabras un exceso de pesimismo. Cuando comencé mi experiencia académica en Estados Unidos lo hice con una ponencia que titulé, robándole las palabras a Vallejo, "Contra el secreto profesional". Allí mostré mi desengaño frente a un gremio que parecía haber perdido toda capacidad autocrítica y en el cual se iba imponiendo una permisividad sin duda preocupante. Creo que exageré porque mis ejemplos eran rabiosamente contundentes pero provenían de pocas fuentes. Ahora no quisiera que mis palabras fueran consideradas como un presagio sino como un preocupado y cordial señalamiento de los que pudiera ser el deshilachado y poco honroso final del hispanoamericanismo. 